\title{
New Approach to Pull-In Limit and Position Control of Electrostatic Cantilever Within the Pull-In Limit
}

\author{
Ali Yildiz ${ }^{1}$, Cevher Ak ${ }^{1}$ and Hüseyin Canbolat ${ }^{2}$ \\ ${ }^{1}$ Mersin University, Electrical and Electronics Engineering Department, Mersin, \\ ${ }^{2}$ Yildirim Beyazit University, Department of \\ Electronics and Communication Engineering, Ankara, \\ 1,2Turkey
}

\section{Introduction}

Since electrostatic cantilevers are very easy to fabricate, have small dimension, and consume low power, they have been very popular as a sensor. They had been used as a capacitive pressure sensor for measuring blood pressure (Hin-Leung Chau \& Wise, 1988), as a microwave switch (Dooyoung Hah et al., 2000), as an air flow sensor (Yu-Hsiang Wang et al., 2007), as a micro-actuator for probe-based data storage (Lu \& Fedder, 2004), and in well known commercial applications like inkjet head (Kamusuki et al., 2000), and optical scanners (Schenk et al., 2000).

An electrostatic MEMS cantilever is a simple capacitor consists of two parallel conductive plates. The bottom conductive plate is coated on a substrate and fixed on it, the top plate is suspended with a surface area $A$. The top electrode is separated by a gap spacing $d$ above the bottom one and fixed from one end. The other end is free to move. When a potential difference $(\mathrm{V})$ is applied between electrodes, free end will tilt downwards $(\delta)$ due to electrostatic force (Fig.1.)

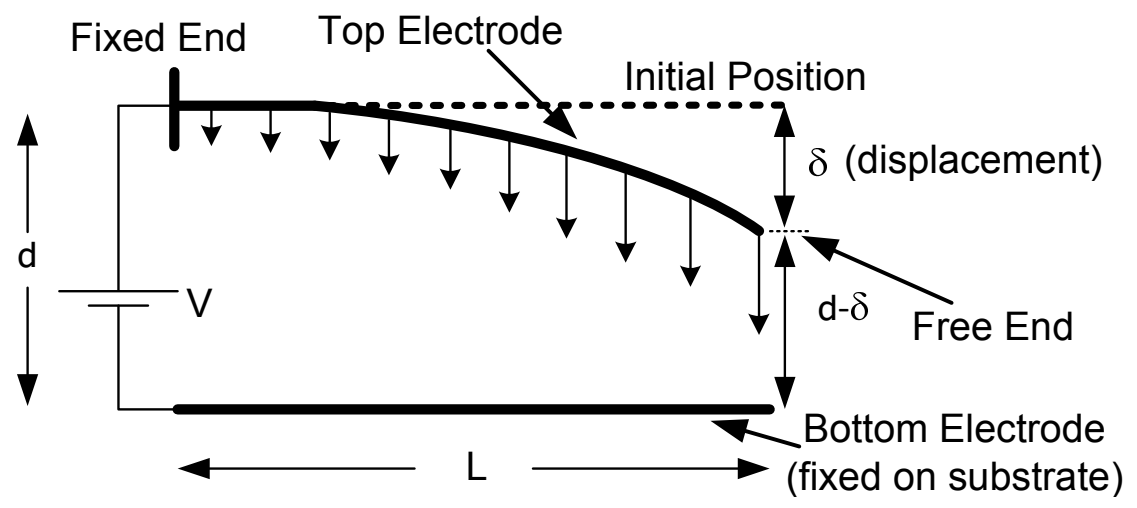

Fig. 1. Electrostatic actuator (Side View) 
When potential difference is removed, top electrode will come back to its initial (original) position due to restoring force of the bended structure. It is also sometimes called as spring force. If applied potential is increased beyond the some limit, top electrode will collapse onto the bottom electrode. While spring force term is proportional with the displacement, electrostatic force is proportional to square of the displacement. Hence, after some point, spring force cannot balance the electrostatic force any more. Then, top electrode collapses onto the bottom electrode. This point is named as pull-in limit.

Because cantilever is an electromechanical coupled system, its behavior is non-linear. Thus, having an analytical formula for pull-in limit is impossible. So, there is no simple formula to calculate it. People have been using lumped model (Hyun-Ho Yang et al., 2010; Seeger \& Boser, 1999; Nielson \& Barbastathis, 2006; Faris et al., 2006; Mol et al., 2007; Chowdhury et al., 2006; Owusu \& Lewis, 2007) for decades. Lump model estimates the pull-in limit as one-third of the initial gap (d/3). However, experimental part of a study showed that pull-in limit is at a different value (Hu et al., 2004). Hu et al. utilized a linearized governing equation of a cantilever to demonstrate their analytical approach. They obtained the total energy expressions including the kinetic energy, strain energy, and electric potential energy. The total energy expression was substituted into Hamilton's principle, and obtained partial differential equation with a nonlinear force term. This force term expanded by Taylor series about the equilibrium position and higher order terms neglected with an assumption of small displacement. At the end, structureelectrostatic coupling linear partial differential equation was obtained. Since small deflection was assumed and Taylor series expanded about equilibrium position, as the cantilever tip gets away from initial (original) position, error percentage also gets bigger (as high as $10 \%$ ) when the tip is closer to pull-in limit(Hu et al., 2004). A later study has used Generalized Differential Quadrature Method which is accurate and efficient way to analyze a linear vector space by high-order polynomial approximation (Sadeghian et al., 2007). This approach gives smaller error in some measurements but not in all of them. Error gets as high as 5\% when we close to pull-in limit.

When it is also checked by a software (ANSYS) which utilizes finite element method, pull-in limit seems to be at around $44 \%$ of initial gap which is consistent with experimental results (Hu et al., 2004; Sadeghian et al., 2007). Table 1 shows some simulation results for different initial gaps.

\begin{tabular}{|l|l|l|}
\hline Initial Gap $(\boldsymbol{\mu m})$ & Pull-in Gap $(\mu \mathrm{m})$ & Pull-in Gap/Initial Gap \\
\hline 2 & 0.881 & 0.4405 \\
\hline 5 & 2.203 & 0.4406 \\
\hline 10 & 4.403 & 0.4403 \\
\hline
\end{tabular}

Table 1. Ansys simulation Pull-in results of a cantilever with $\mathrm{L}=200 \mu \mathrm{m}$.

These results show that the lumped model is not a very good approximation of the system. In fact, the cantilever beam system has two constrains: fixed end of the top electrode has zero displacement and zero angle even when voltage applied between electrodes. However, lumped model considers only second constrain for the sake of simplicity. 


\section{Lumped model}

As it can be seen from Fig. 2, only zero angle constrain is considered and zero displacement is ignored. Nevertheless, the model is very simple. Therefore, calculations are easy and pullin limit can be computed in few steps as one-third of the initial gap.

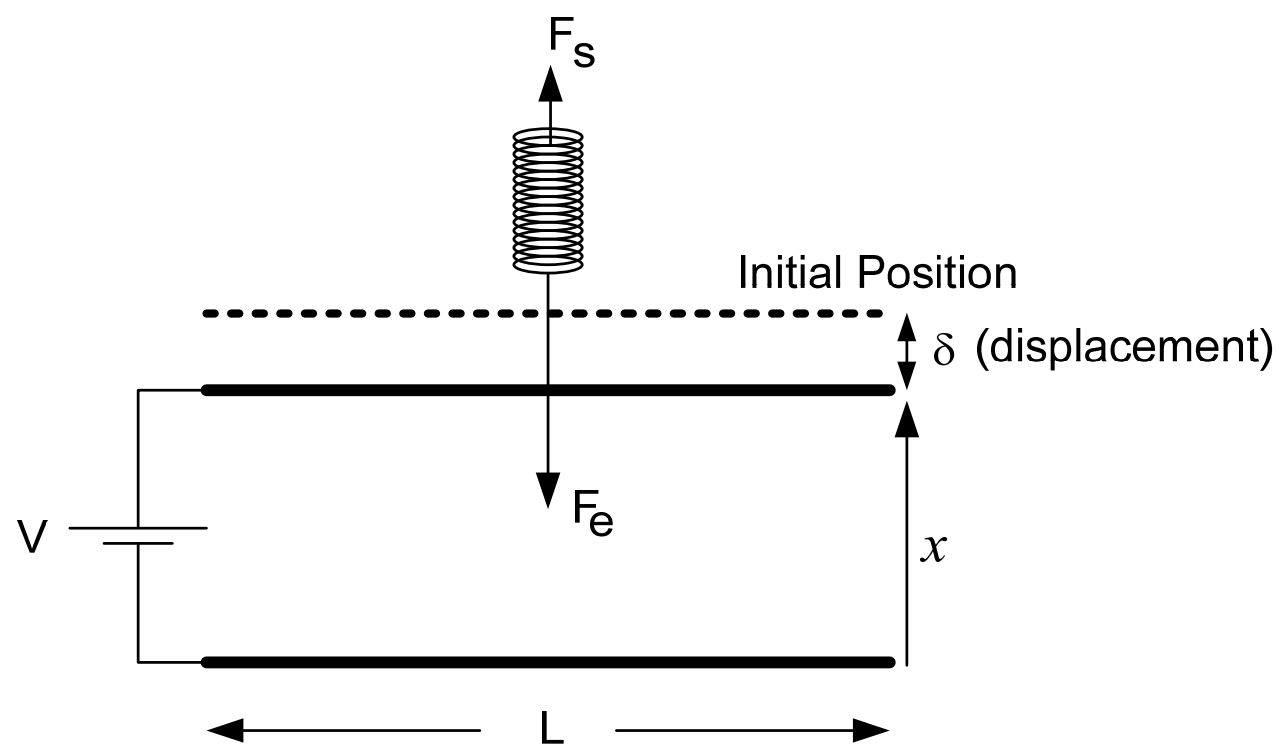

Fig. 2. Lumped model of a cantilever actuator.

Stored energy in a parallel plate capacitor is

$$
\mathrm{U}=\frac{1}{2} \mathrm{CV}^{2}
$$

Force due to this energy is

$$
\mathrm{F}=\frac{\mathrm{dU}}{\mathrm{dx}}
$$

Therefore,

$$
\mathrm{F}=\frac{\mathrm{d}}{\mathrm{dx}}\left(\frac{1}{2} \mathrm{CV}^{2}\right)=\frac{1}{2} \frac{\mathrm{dC}}{\mathrm{dx}} \mathrm{V}^{2} \quad\left(\frac{\mathrm{dV}}{\mathrm{dx}}=0 \text { since } \mathrm{V} \text { is constant }\right)
$$

Value of a parallel plate capacitor is

$$
C=\frac{\varepsilon_{0} \mathrm{~A}}{\mathrm{x}}
$$

$\varepsilon_{0}$ is permittivity of free space, $\mathrm{A}$ is area of one of the parallel plates, and $\mathrm{x}$ is the distance between plates. 
So,

$$
\frac{\mathrm{dC}}{\mathrm{dx}}=-\frac{\varepsilon_{0} \mathrm{~A}}{\mathrm{x}^{2}}
$$

Then, electrostatic force term is

$$
\mathrm{F}_{\mathrm{e}}=-\frac{\varepsilon_{0} A \mathrm{AV}^{2}}{2 \mathrm{x}^{2}} \quad(- \text { sign shows direction of the force })
$$

Electrostatic force term and spring force term will be equal to each other for equilibrium,

$$
\begin{gathered}
\mathrm{F}_{\mathrm{e}}=\mathrm{F}_{\mathrm{s}} \\
\frac{\varepsilon_{0} \mathrm{AV}^{2}}{2 \mathrm{x}^{2}}=\mathrm{k} \delta, \quad \delta=(\mathrm{d}-\mathrm{x}) \\
2 \mathrm{k}\left(\mathrm{x}^{2} \mathrm{~d}-\mathrm{x}^{3}\right)=\varepsilon_{0} A V^{2}
\end{gathered}
$$

Potential can be get as

$$
V=\sqrt{\frac{2 k}{\varepsilon_{0} A}\left(x^{2} d-x^{3}\right)}
$$

Top electrode will collapse when

$$
\frac{\mathrm{dV}}{\mathrm{dx}}=0
$$

So, if derivative is taken of Eq. (10) we have

$$
2 x d-3 x^{2}=0
$$

Then critical $x$ value can be get as

$$
\mathrm{x}_{\text {critical }}=\frac{2}{3} \mathrm{~d}
$$

Displacement of top electrode at the limit condition can be found as

$$
\delta_{\text {critical }}=\frac{1}{3} \mathrm{~d}
$$

Thus, critical value of the potential difference can be calculated as

$$
\mathrm{V}_{\text {critical }}=\sqrt{\frac{2 \mathrm{k}}{\varepsilon_{0} \mathrm{~A}}\left(\frac{2}{3} \mathrm{~d}\right)^{2} \mathrm{~d}-\left(\frac{2}{3} \mathrm{~d}\right)^{3}}
$$

Therefore, it can be simplified as 


$$
\mathrm{V}_{\text {critical }}=\sqrt{\frac{8}{27} \frac{\mathrm{kd}^{3}}{\varepsilon_{0} \mathrm{~A}}}
$$

$k$ can be obtained for a cantilever as (Saha et al., 2006)

$$
\mathrm{k}=\frac{2}{3} \mathrm{Ew}\left(\frac{\mathrm{t}}{\mathrm{L}}\right)^{3}
$$

and insert this in Eq. (16), and replace $A$ with wL. We can get

$$
\mathrm{V}_{\text {critical }}=\sqrt{\frac{16 \mathrm{Ed}^{3} \mathrm{t}^{3}}{81} \frac{\varepsilon_{0} \mathrm{~L}^{4}}{}}
$$

\section{Bisection model}

Since model has two different sections, it is named as Bisection Model and can be seen in Fig.3. Bisection model considers two constrains of fixed end of the top electrode. Fixed end has both zero displacement and zero angle while the other end is free to tilt linearly around pivot. Pivot point is placed $1 / 3$ of the cantilever length from fixed end of top electrode. There is no specific reason for $1 / 3$ ratio exactly. Since, the left side of the cantilever is fixed, there is very small movement at the left side. So, we model the structure in a that way $1 / 3$ of the cantilever is not moving at all and rest is moving linearly around the break point (pivot). By doing this, we still have very simple model as Lumped model and also consider both constraint of fixed end. Therefore, we can have a simple formula for the structure. Electrostatic force is placed at the free end of the top electrode since this end is close to bottom electrode and force gets its biggest value over there. Restoring force is placed at the one third of the movable part since it has to be close to pivot.

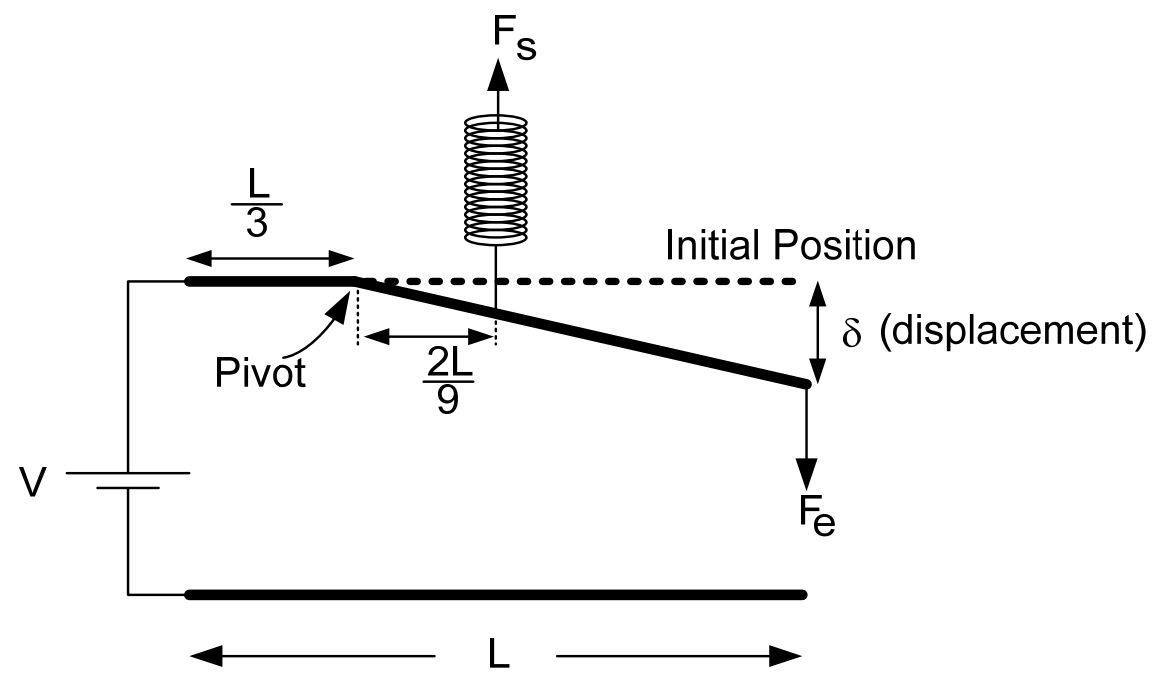

Fig. 3. New Approach (Bisection Model) to cantilever actuator. 
In this model, capacitance of the system has two parts (see Fig. 4.)

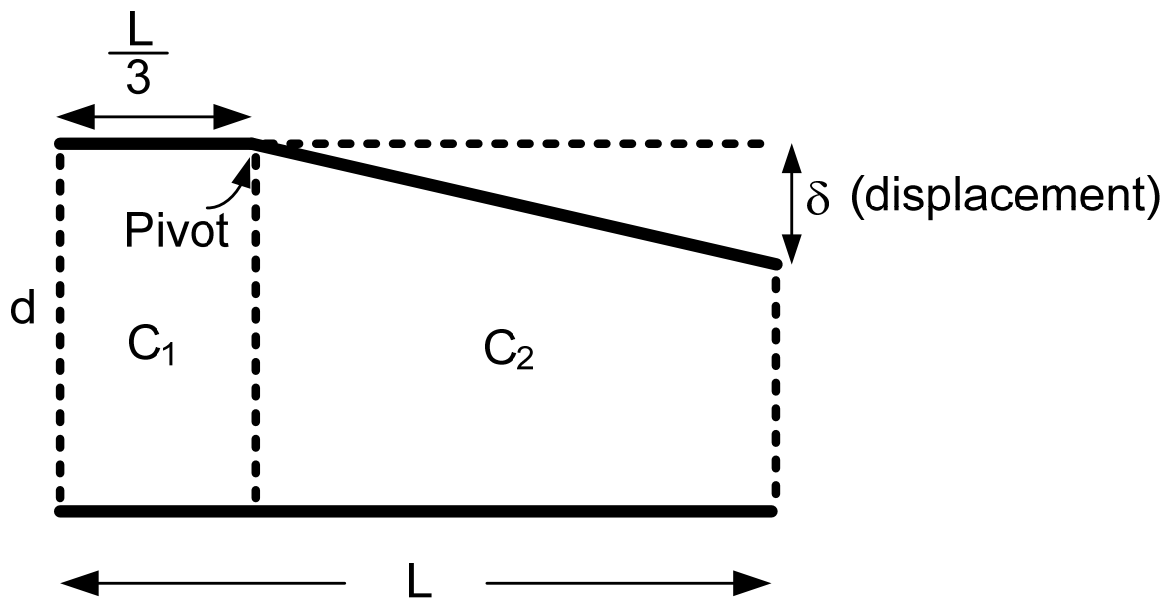

Fig. 4. Bisection Model capacitor calculation.

$\mathrm{C}_{1}$ and $\mathrm{C}_{2}$ can be found as

$$
C_{1}=\varepsilon_{0} \frac{w L}{3 d} \quad \text { and } C_{2}=\frac{2 \varepsilon_{0} w L}{3 \delta} \ln \left(\frac{d}{d-\delta}\right)
$$

Where $\mathrm{w}$ and $\mathrm{L}$ are width and length of the cantilever respectively.

Therefore, total capacitance of the system is

$$
\mathrm{C}_{\mathrm{T}}=\mathrm{C}_{1}+\mathrm{C}_{2}=\frac{1}{3} \varepsilon_{0} \mathrm{wL}\left(\frac{1}{\mathrm{~d}}+\frac{2}{\delta} \ln \left(\frac{\mathrm{d}}{\mathrm{d}-\delta}\right)\right)
$$

And electrostatic force term can be obtained as

$$
\mathrm{F}_{\mathrm{e}}=\frac{1}{2}\left[\left(\frac{\mathrm{d}}{\mathrm{d} \delta}\left(\mathrm{C}_{1}+\mathrm{C}_{2}\right)\right) \mathrm{V}^{2}+\left(\frac{\mathrm{d}}{\mathrm{d} \delta} \mathrm{V}^{2}\right)\left(\mathrm{C}_{1}+\mathrm{C}_{2}\right)\right]
$$

Since $V$ (potential difference between electrodes) is constant between plates and $C_{1}$ is also constant, equation can be written shortly as

$$
\mathrm{F}_{\mathrm{e}}=\frac{1}{2} \frac{\mathrm{dC} \mathrm{C}_{2}}{\mathrm{~d} \delta} \mathrm{V}^{2}
$$

Since

$$
\frac{\mathrm{dC}_{2}}{\mathrm{~d}(\mathrm{~d}-\delta)}=\frac{2}{3}\left(-\frac{\varepsilon_{0} \mathrm{wL} \ln \left(\frac{\mathrm{Ld}}{\mathrm{Ld}-\mathrm{L} \delta}\right)}{\delta^{2}}+\frac{\varepsilon_{0} \mathrm{wL}^{2}}{\delta \mathrm{L}(\mathrm{d}-\delta)}\right)
$$


The electrostatic force term can be obtained as

$$
F_{e}=\frac{1}{3} \varepsilon_{0} w L\left(\frac{-\ln \left(\frac{d}{d-\delta}\right) d+\ln \left(\frac{d}{d-\delta}\right) \delta+\delta}{\delta^{2}(d-\delta)}\right) V^{2}
$$

The storing force term can be written as

$$
\mathrm{F}_{\mathrm{s}}=\mathrm{k} \frac{\delta}{3}
$$

and $k$ can be obtained for a cantilever as (Saha et al., 2006)

$$
\mathrm{k}=\frac{2}{3} \mathrm{Ew}\left(\frac{\mathrm{t}}{\mathrm{L}}\right)^{3}
$$

Where E and t are Young's modulus and thickness of top electrode.

In the Bisection Model only $2 L / 3$ part of the upper electrode is free to move. So, by substituting $2 L / 3$ to $L, k$ can be calculated as

$$
\mathrm{k}=\frac{9}{4} \mathrm{Ew}\left(\frac{\mathrm{t}}{\mathrm{L}}\right)^{3}
$$

for Bisection Model. Since moments of the electrostatic and restoring forces are equal, we can write

$$
\frac{6}{9} \mathrm{~F}_{\mathrm{e}}=\frac{2}{9} \mathrm{~F}_{\mathrm{s}}
$$

Therefore, the relation between applied voltage and displacement is given by

$$
V=\left(\frac{3}{4} \frac{\mathrm{Et}^{3} \delta^{3}(\mathrm{~d}-\delta)}{\varepsilon_{0} \mathrm{~L}^{4}\left(-\ln \left(\frac{\mathrm{d}}{\mathrm{d}-\delta}\right) \mathrm{d}+\ln \left(\frac{\mathrm{d}}{\mathrm{d}-\delta}\right) \delta+\delta\right.}\right)^{\frac{1}{2}}
$$

This equation is valid not only for pull-in limit, but also for all values within the pull-in limit.

To find the pull-in limit, we have to take derivative of $V$ with respect to $\delta$. So;

$$
\frac{d V}{d \delta}=\frac{-\frac{\sqrt{3} E t^{3}}{4}\left(4 \delta^{2}-3 d \delta+\left(3 \delta^{2}-6 \delta d+3 d^{2}\right) \ln \left(\frac{d}{d-\delta}\right)\right)}{\left(\delta E t^{3}(d-\delta) L^{4} \varepsilon_{0}\left(\ln \left(\frac{d}{d-\delta}\right)(\delta-d)+\delta\right)^{3}\right)^{\frac{1}{2}}}=0
$$


There is no analytical solution to this equation. Hence, computational result has been obtained as:

$$
\frac{\delta_{\max }}{d}=0.440423
$$

In addition, when a graph of the equation is drawn, it shows stable and unstable regions (Fig. 5). It can be seen that the Pull-in Limit is at the $44 \%$ of the initial gap.

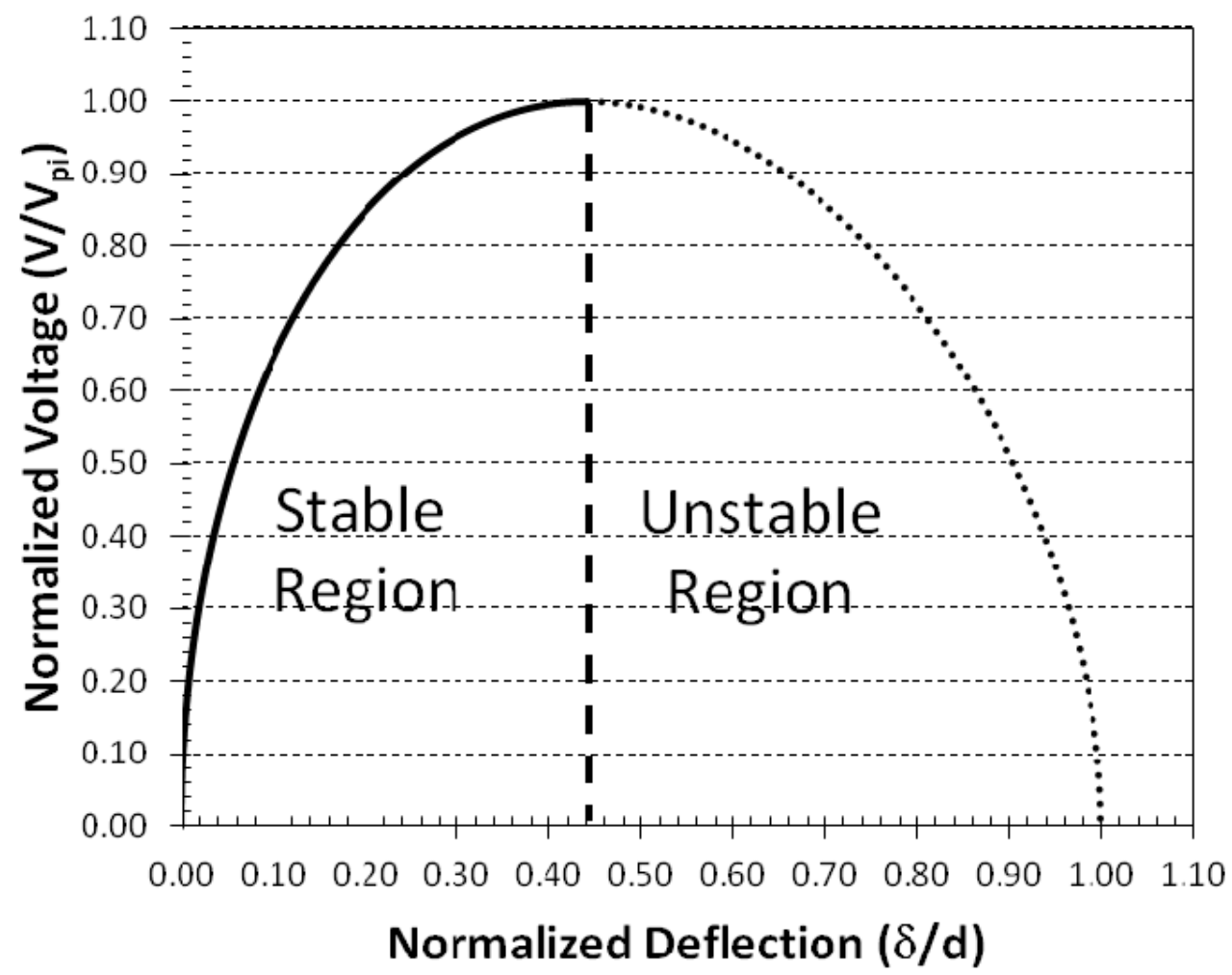

Fig. 5. Stable and Unstable Regions of Bisection Model.

Thus, critical value of the potential difference can be calculated as

$$
\mathrm{V}_{\text {critical }}=\sqrt{\frac{69}{500} \frac{\mathrm{kd}^{3}}{\varepsilon_{0} \mathrm{~A}}}
$$

and insert Eq. (27) into Eq. (32), and replace $A$ with wL. We can get

$$
V_{\text {critical }}=\sqrt{\frac{621}{2000} \frac{\mathrm{Ed}^{3} \mathrm{t}^{3}}{\varepsilon_{0} \mathrm{~L}^{4}}}
$$


Eq. (33) is very similar with Lumped Model's Eq. (18) except coefficient which helps to get better results when compared with Lumped Model.

Table 2 and 3 show comparison of Ansys simulation results and values obtained from Bisection Model and percentage error for cantilever with different lengths.

\begin{tabular}{|l|l|l|l|}
\hline \multicolumn{1}{|c|}{ (Initial gap=2 $\mu \mathrm{m})$} & \multicolumn{1}{|c|}{\begin{tabular}{c}
\multicolumn{1}{c|}{$\mathbf{V}_{\max }(\mathrm{V})$} \\
From Bisection Model
\end{tabular}} & $\begin{array}{c}\mathbf{V}_{\max }(\mathbf{V}) \\
\text { From ANSYS }\end{array}$ & \multicolumn{1}{c|}{ \% Error } \\
\hline $\mathrm{L}=150$ & 27.4707 & 27.3408 & 0.475 \\
\hline $\mathrm{L}=200$ & 15.4523 & 15.4179 & 0.223 \\
\hline $\mathrm{L}=250$ & 9.8894 & 9.8985 & 0.092 \\
\hline $\mathrm{L}=300$ & 6.8677 & 6.8284 & 0.575 \\
\hline $\mathrm{L}=400$ & 3.8631 & 3.8604 & 0.069 \\
\hline $\mathrm{L}=500$ & 2.4724 & 2.4715 & 0.036 \\
\hline
\end{tabular}

Table 2. Comparison of $\mathrm{V}_{\max }$ (Pull-in Voltage) values for cantilevers with different lengths

\begin{tabular}{|l|l|l|l|}
\hline \multicolumn{1}{|c|}{$(\mathbf{L}=\mathbf{1 5 0} \boldsymbol{\mu m}, \mathbf{d = 2} \boldsymbol{\mu m})$} & \multicolumn{1}{|c|}{$\begin{array}{c}\text { Voltage }(\mathbf{V}) \\
\text { From Bisection Model }\end{array}$} & \multicolumn{1}{c|}{$\begin{array}{c}\text { Voltage (V) } \\
\text { From ANSYS }\end{array}$} & \% Error \\
\hline$\delta=0.01415(0.71 \%)$ & 5.0549 & 5.0 & 1.098 \\
\hline$\delta=0.05829(2.91 \%)$ & 10.1072 & 10.0 & 1.072 \\
\hline$\delta=0.1386(6.93 \%)$ & 15.1544 & 15.0 & 1.030 \\
\hline$\delta=0.2714(13.57 \%)$ & 20.1942 & 20.0 & 0.971 \\
\hline$\delta=0.5165(25.83 \%)$ & 25.2056 & 25.0 & 0.822 \\
\hline$\delta=0.6028(30.14 \%)$ & 26.1918 & 26.0 & 0.737 \\
\hline$\delta=0.7419(37.10 \%)$ & 27.1588 & 27.0 & 0.588 \\
\hline$\delta=0.7654(38.27 \%)$ & 27.2542 & 27.1 & 0.569 \\
\hline$\delta=0.7963(39.82 \%)$ & 27.3518 & 27.2 & 0.558 \\
\hline$\delta=0.8146(40.73 \%)$ & 27.3949 & 27.25 & 0.531 \\
\hline$\delta=0.8808(44.04 \%)$ & 27.4628 & 27.34 & 0.449 \\
\hline
\end{tabular}

Table 3. Comparison of Voltage values for arbitrary $\delta$ displacements. 
Table 4 shows comparison of previous experimental, analytical results (Hu et al., 2004; Sadeghian et al., 2007), Bisection Model Result, and percentage error with respect to experimental results. Ansys simulation results also added for comparison.

\begin{tabular}{|l|l|l|l|l|l|}
\hline Voltage(V) & $\begin{array}{c}\text { Experimental } \\
\text { (Hu et al., } \\
\text { 2004) }\end{array}$ & $\begin{array}{c}\text { Analytical (Hu } \\
\text { et al., 2004) } \\
/ \text { (Error) }\end{array}$ & $\begin{array}{c}\text { Analytical } \\
\text { (Sadeghian } \\
\text { et al., 2007) } \\
/ \text { (Error) }\end{array}$ & $\begin{array}{c}\text { Bisection } \\
\text { Model / } \\
\text { (\%Error) }\end{array}$ & ANSYS \\
\hline 20 & 90.5 & $90.2 /(0.3 \%)$ & $90.2 /(0.3 \%)$ & $90.4 /(0.1 \%)$ & 90.4 \\
\hline 40 & 84.6 & $84.3 /(0.4 \%)$ & $84.1 /(0.6 \%)$ & $85.1 /(0.6 \%)$ & 85.1 \\
\hline 60 & 70.0 & $71.5 /(2.1 \%)$ & $69.1 /(1.2 \%)$ & $73.2 /(4.5 \%)$ & 73.2 \\
\hline 65 & 64.0 & $67.2 /(5.0 \%)$ & $59.6 /(6.9 \%)$ & $67.4 /(5.3 \%)$ & 67.6 \\
\hline 67 & 59.0 & $65.0 /(10.2 \%)$ & - & $64.1 /(8.7 \%)$ & 64.5 \\
\hline
\end{tabular}

Table 4. Comparison of displacements for different voltage values. Errors are respect to experimental results.

\section{Conclusion}

Values calculated from Bisection Model are very close to those obtained from ANSYS. Especially, when the displacement is larger than $10 \%$ of the initial gap, all the errors are within 1\% (see Table 3). Therefore, Bisection Model not only gives a better pull-in limit when compared with previous lumped model, but also has simpler analytical result when compared with previous discrete models. At the same time, it gives satisfactory results for applied voltages for given displacements of top electrode's free end. Bisection Model is also very successful when compared to experimental studies. Percentage error level of Bisection Model is comparable when displacement is small, and gets better when displacement is close to pull-in limit (see Table 4). Bisection Model also gives a simple formula to use instead of using numerical methods which is time consuming and requires computation capacity.

\section{References}

Chowdhury, Sazzadur.; Ahmadi, Majid. \& Miller, W. C. (2006). Pull-in Voltage Study of Electrostatically Actuated Fixed-Fixed Beams Using a VLSI On-Chip Interconnect Capacitance Model. IEEE journal ofMEMS, vol.15, no.3, pp.639-651, ISSN 10577157

Dooyoung Hah.; Euisik Yoon. \& Songheol Hong. (2000). A Low-Voltage Actuated Micromachined Microwave Switch Using Torsion Springs ans Leverage. Microwave Symposium Digest, vol.1, pp.157-160, ISSN 0149-645X

Faris, W.F.; Mohammed H.M.; Abdalla, M.M. \& Ling, C.H. (2006). Influence of MicroCantilever Geometry and Gap on Pull-in Voltage. Dans Symposium on Design, Test, 
Integration and Packaging of MEMS/MOEMS, DTIP 2006, Stresa, Lago Maggiore : Italie (2006)

Hin-Leung Chau. \& Wise, K.D. (1988). An ultraminiature solid-state pressure sensor for a cardiovascular catheter. IEEE Trans. Electronic Devices, vol.35, No.12, pp. 2355-2362, ISSN 0018-9383

$\mathrm{Hu}$, Y.C.; Chang, C.M. \& Huang S.C. (2004). Some Design Considerations on the electrostatically actuated microstructures. Sensors and Actuators, vol.112, no.11, pp.155-161 ISSN 0924-4247

Hyun-Ho Yang.; Jeong Oen Lee. \& Jun-Bo Yoon. (2010). Maneuvering Pull-in Voltage of an Electrostatic Micro-Switch by Introducing a Pre-charged Electrode. MEMS, 2010 IEEE 23 ${ }^{\text {rd }}$ International Conference on, Wanchai, Hong Kong, 24-28 Jan., pp.747-750, ISSN 1084-6999

Kamusuki, S.; Fujii, M.; Takekoshi, T. \& Tekuza, C. (2000) A high resolution, electrostatically driven commercial inkjet head. Proceedings of IEEE MEMS 2000 conference, Miyazaki, Japan, 23-27 Jan., pp. 793-798.

Lu, M.S.-C. \& Fedder, G.K. (2004). Position Control of Parallel-Plate Microactuators for Probe-Based Data Storage. IEEE Journal of MEMS, vol.12 no.5, pp.759-769, ISSN 1057-7157

Mol, Lukas.; Rocha, Luis A.; Cretu, Edmond. \& Wolffenbuttel, Reinoud F. (2007). Full-Gap Positioning of Parallel-Plate Electrostatic MEMS Using On-off Control. IEEE Int. Symposium on Industrial Electronics, ISIE2007, Vigo, Spain, pp.1464-1468

Nielson G. N. \& Barbastathis, George. (2006). Dynamic Pull-in of Parallel-Plate and Torsional Electrostatic MEMS Actuators. IEEE MEMS Journal, vol.15, no.4, pp.811821, ISSN 1057-7157

Owusu, Kwadwo O. \& Lewis, Frank L. (2007). Solving the Pull-in Instability Problem of Electrostatic Microactuators Using Nonlinear Control Techniques. Nano/Micro Engineered and Molecular Systems, 2007. NEMS '07. 2nd IEEE International Conference on, 16-19 Jan, Bangkok, pp.1190-1195

Sadeghian, Hamed.; Rezazadeh, Ghader. \& Osterberg, Peter M. (2007). Application of the Generalized Differential Quadrature Method to the Study of Pull-in Phenomena of MEMs Switches. Journal of Microelectromechanical Systems, Vol. 16,No. 6, pp. 13341340 ISSN 1057-7157

Saha, S. C.; Hanke, U.; Jensen, G. U. \& Saether, T. (2006). Modeling of Spring Constant and Pull-down Voltage of Non uniform RF MEMS Cantilever. IEEE Behavioral Modeling and Simulation Workshop, s.56-60,

Schenk, H.; Durr, P.; Kunze, D.; Lakher, H. \& Kuck, H. (2000). An electrostatically excited 2D-micro scanning-mirror with an in plane configuration of the driving electrodes. Proceedings of IEEE MEMS 2000 Conference, Miyazaki, Japan, 23-27 Jan., pp. 473-478.

Seeger, Joseph I. \& Boser, Bernhard E. (1999). Dynamics and Control of Parallel-Plate Actuators Beyond the Electrostatic Instability. 10 th International Conf. on Solid-Stade Sensor and Actuators, Sendai, Japan, 7-9 June, pp.474-477 
Yu-Hsiang Wang.; Chia-Yen Lee. \& Che-Ming Chiang. (2007). A Mems-based Air Flow Sensor with a Free-Standing Microcantilever Structure. Sensors, vol.7, no.10, pp.2389-2401 


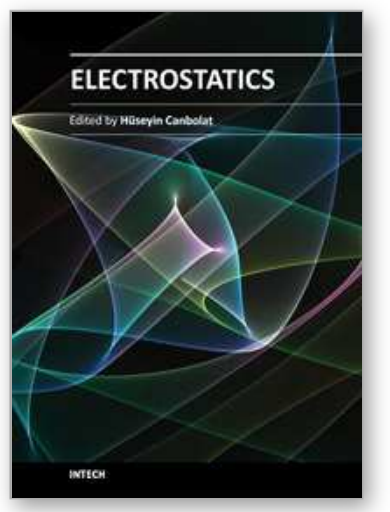

\author{
Electrostatics \\ Edited by Dr. Hüseyin Canbolat
}

ISBN 978-953-51-0239-7

Hard cover, 150 pages

Publisher InTech

Published online 14, March, 2012

Published in print edition March, 2012

In this book, the authors provide state-of-the-art research studies on electrostatic principles or include the electrostatic phenomena as an important factor. The chapters cover diverse subjects, such as biotechnology, bioengineering, actuation of MEMS, measurement and nanoelectronics. Hopefully, the interested readers will benefit from the book in their studies. It is probable that the presented studies will lead the researchers to develop new ideas to conduct their research.

\title{
How to reference
}

In order to correctly reference this scholarly work, feel free to copy and paste the following:

Ali Yildiz, Cevher Ak and Hüseyin Canbolat (2012). New Approach to Pull-In Limit and Position Control of Electrostatic Cantilever Within the Pull-in Limit, Electrostatics, Dr. Hüseyin Canbolat (Ed.), ISBN: 978-953-510239-7, InTech, Available from: http://www.intechopen.com/books/electrostatics/new-approach-to-pull-in-limitand-position-control-of-electrostatic-cantilever-within-the-pull-in-li

\section{INTECH}

open science | open minds

\section{InTech Europe}

University Campus STeP Ri

Slavka Krautzeka 83/A

51000 Rijeka, Croatia

Phone: +385 (51) 770447

Fax: +385 (51) 686166

www.intechopen.com

\section{InTech China}

Unit 405, Office Block, Hotel Equatorial Shanghai

No.65, Yan An Road (West), Shanghai, 200040, China

中国上海市延安西路65号上海国际贵都大饭店办公楼405单元

Phone: +86-21-62489820

Fax: +86-21-62489821 
(C) 2012 The Author(s). Licensee IntechOpen. This is an open access article distributed under the terms of the Creative Commons Attribution 3.0 License, which permits unrestricted use, distribution, and reproduction in any medium, provided the original work is properly cited. 